This item was submitted to Loughborough's Research Repository by the author.

Items in Figshare are protected by copyright, with all rights reserved, unless otherwise indicated.

\title{
'Did you ever hear of police being called to a beer festival?' Discourses of merriment, moderation and 'civilized' drinking amongst real ale enthusiasts
}

PLEASE CITE THE PUBLISHED VERSION

http://dx.doi.org/10.1111/1467-954X.12361

\section{PUBLISHER}

(c) The Author. Published by SAGE.

\section{VERSION}

AM (Accepted Manuscript)

\section{PUBLISHER STATEMENT}

This work is made available according to the conditions of the Creative Commons Attribution-NonCommercialNoDerivatives 4.0 International (CC BY-NC-ND 4.0) licence. Full details of this licence are available at: https://creativecommons.org/licenses/by-nc-nd/4.0/

\section{LICENCE}

CC BY-NC-ND 4.0

\section{REPOSITORY RECORD}

Thurnell-Read, Thomas P.. 2019. "'did You Ever Hear of Police Being Called to a Beer Festival?' Discourses of Merriment, Moderation and 'civilized' Drinking Amongst Real Ale Enthusiasts". figshare. https://hdl.handle.net/2134/21453. 
'Did you ever hear of police being called to a beer festival?': Discourses of Merriment, Moderation and 'Civilized' Drinking Amongst Real Ale Enthusiasts

Thurnell-Read, T. (2016). 'Did you ever hear of police being called to a beer festival?'Discourses of merriment, moderation and 'civilized'drinking amongst real ale enthusiasts. The Sociological Review.

DOI: 10.1111/1467-954X.12361

\section{Dr Thomas Thurnell-Read}

Department of Social Sciences

Loughborough University

Loughborough

LE11 3TU, UK

Email: t.thurnell-read@lboro.ac.uk 


\title{
'Did you ever hear of police being called to a beer festival?': Discourses of Merriment, Moderation and 'Civilized' Drinking Amongst Real Ale Enthusiasts
}

\begin{abstract}
While the real and perceived excesses of 'binge drinking' have received considerable attention in policy, media and academic debates, the concept of 'sensible drinking' is poorly defined and has rarely been subject to empirical analysis. Using qualitative research, this article explores the drinking discourses of ale enthusiasts as a means of highlighting how understandings of sensible drinking draw on notions of taste, sociability and self-control. Drawing on Elias's concept of the 'civilizing process', the article analyses how these narratives highlight self-control and social regulation as central features of acceptable drinking practices. Emerging from these accounts is a rejection of elements of the night-time economy and the unruly and hedonistic 'determined drunkenness' often associated with it.
\end{abstract}

\section{Key Words}

Alcohol, Civilizing Process, Drunkenness, Elias, Moderation, Student Drinking

\section{Introduction}

The 'spectacle of binge drinking' has come to dominate media, policy and academic debates about the role of alcohol and drunkenness in contemporary British society (Plant and Plant, 2006; Hayward and Hobbs, 2007). The drunken excesses of British university students, of rowdy 'stag tourists', and of pleasure-seeking British package holiday-makers (see respectively Hubbard, 2013; Thurnell-Read, 2011a; and Andrews, 2011) make ready fodder for sensationalist media coverage replete with depictions of unrestrained hedonism, antisocial behaviour and violence. Such 'determined drunkenness', where alcohol is consumed rapidly and with the specific and primary intention of achieving a state of inebriation, is said to define a 'new culture of intoxication' characterised by the absence of 'certain individual social constraints surrounding public drunkenness' (Measham and Brain, 2005: 273).

In contrast to this picture of excess, the practices of those who moderate alcohol consumption, or abstain entirely, have rarely been explored in academic work (notable exceptions being Valentine et al, 2010; Herrin et al, 2012; Romo, 2012). Successive government reports and policy documents have sought to promote 'sensible drinking' (Interdepartmental Working Group, 1995; Engineer et al, 2003; Cabinet Office, 2004; HM Government, 2007; HM Government, 2012) and frequent 
reference is made to 'social' and 'sensible' drinking in media and policy debates. Yet, as Ball, Williamson and Witton (2007: 101) observe, 'the sensible drinking message is confused and poorly understood'. What constitutes 'sensible' drinking is rarely defined beyond drinking within alcohol consumption limits set by Government guidelines in terms of unit' consumption (Eldridge and Roberts, 2008). As Yeomans (2013) suggests in a detailed analysis of regulatory strategies which frequently draw on 'expertise' and 'evidence', a precise definition of moderate drinking remains allusive, being as it is a contested 'fluid' term.

A further trend in both media and policy discourse is the ready use of 'spatial metaphors' where the distinctly 'British disease' of antisocial binge drinking is juxtaposed to the 'civilized' social drinking of 'continental', 'Mediterranean' or 'European' drinking cultures (Tierney, 2006; Järvinen and Room, 2007; Jayne et al, 2008). Indeed, 'civilized' drinking has become part of a quest amongst planning officials for a diverse and balanced urban economy (Latham, 2003; Hollands and Chatterton, 2010; Haydock, 2014a, 2014b). Problematically, then, media and government reports tend to reduce drinkers 'to either civilised 'social drinkers' or "binge drinking urban savages" (Eldridge and Roberts, 2008: 366). Such dominant discourses fail to acknowledge that 'drinking practice and experiences are diverse and heterogeneous' (Jayne et al, 2010: 546). Further, they also tend to place culpability for any failure to conform to normative standards solely with individual drinkers and in doing so largely ignore both the complexity of social and cultural context in the present and the contingencies of changing social relations and standards of conduct over time. Indeed, there are recent indications that drinking levels are once again falling in Britain, especially amongst the very groups that policy and academic outputs have emphasised as being the culprits of the worst excesses (McVeigh and O'Neill, 2012; ONS, 2015).

In spite of numerous reference to 'civilized' and 'uncivilized' drinkers and drinking practices in both popular and academic debates, with the notable exception of Rohloff $(2011 ; 2013)$, there has surprisingly been no attempt to make use of Norbert Elias' work on the civilizing processii (Elias, 1969, 1982, 2000; Elias and Dunning, 1986) to better understand how notions of civilization, restraint and self-regulation inform our understanding of what constitutes socially acceptable, and conversely unacceptable, drinking and drunkenness. This article adds to these debates by exploring the discourses deployed by ale enthusiasts who frame their drinking as responsible and social, yet, with only a few exceptions (Spracklen et al, 2013; Thurnell-Read, 2016), remain a largely under-theorised group of drinkers. That is not to say that real ale enthusiasts drink less than other drinkers; indeed, the majority of research participants regularly drink in excess of government guidelines relating to supposed safe drinking limits. Rather, in their accounts they speak of conduct characterised by self-restraint, bodily control and socially embedded conviviality as defining qualities that set their drinking apart from that of others. 


\section{Civilized Drinkers and their 'Others'}

While the focus and language of debates about problem drinkers have changed over time, with the current focus on 'binge drinkers' building on previous concerns about 'lager louts' during the 1980s (Measham and Brain, 2005), there are noticeable continuities between contemporary debates and historical moral panics relating to alcohol as a 'threat to society' (Nicholls, 2009; Rohloff, 2013). Typically, such concerns have focused on particular groups and individuals. Thus, the violent and unruly urban working-class male and the 'vulgar' and 'promiscuous' working-class female (Brown and Gregg, 2012) have long been stock figures in debates about problematic drinking. More recently, Haydock (2014b) has drawn on Bourdieu (1984) to explain how recent policy discourses have relied heavily on class based notions of taste and respectability in in locating some drinkers as irresponsible and therefore appropriate target for moral censure and regulatory intervention.

Young drinkers are frequently held as being particular representative of a new problematic drinking culture characterized by risky behaviour and disorder (Engineer et al, 2003). Of particular concern is the location and setting of much youth drinking; with many young drinkers consuming alcohol first in outdoor unregulated spaces away from the gaze of adult supervision, such as parks and derelict buildings, during their early teens (Coleman and Carter, 2003; Townshend and Roberts, 2013), before progressing to youth oriented high street bars and clubs in their late teens and early twenties. Key studies have identified the significant part played by various 'stakeholders' in the night-time economy (Chatterton and Hollands, 2003; Hadfield, 2006) who produce, sell and regulate corporate drinking venues using 'aesthetic processes aimed at encouraging alcohol-related excitement and excess' (Hayward and Hobbs, 2007: 438). Implicated within this is the decline of inter-generational drinking spaces and an associated socialisation process which has long been seen as a central means of novice drinkers learning the rules and responsibilities of socially accepted drinking practices (see Mass Observation, 1943 and Fox, 2005 for illuminating discussions of drinking rituals and pub etiquette). Thus, there is a fear that the drinking spaces 'where young people learnt sensible consumption under the watchful eye of elders' (Measham, 2008: 216) have been replaced by agesegregated drinking venues which encourage play and disinhibition and, as such, are said to 'infantilise' adults in the night-time economy (Smith, 2014).

Emerging from these debates is a situation where the problematic drinker appears well documented and highly visible in both public and academic discourse - albeit by drawing on a rather narrow range of class, gender and age specific stereotypes while the 'sensible' or 'social' drinker remains ill-defined. While acknowledging that the sensible drinking message 'is hard to apply to the realities of drinking' (Cabinet Office, 2004: 25), government policies have generally adopted a quantified approach to defining 'sensible drinking' within guidelines of units consumed either per week or per day (Ball, Williamson and Witton, 2007; Yeomans, 2013). Where guidance has 
been made to the contextual characteristics of sensible drinking, it has been in reference to 'situations where it is not appropriate to drink' such as before driving, swimming or operating machinery (Interdepartmental Working Group, 1995: 33). This aside, 'sensible drinking' sensible drinking has therefore been defined, rather unsatisfactorily, in opposition and by elimination as not 'binge' drinking, as 'drinking in a way that is unlikely to cause yourself or others a significant risk' (HM Government, 2007: 3). Crucially, perhaps, little regard is given in these documents to the deep-rooted and long apparent cultural and social dimensions of drinking and drunkenness (Douglas, 1987; Thurnell-Read, 2015). As the article aims to illustrate, such guides and measures of intake evidently do little to capture the subjective experiences and understandings of drinking and drunkenness which are heavily contingent upon the embodied and affective qualities of social and physical context (Jayne et al, 2010).

As Yeomans (2011) has suggested, the issues of self-control and self-discipline have a long historical provenance in British debates about alcohol and drunkenness. Thus, in contrast to the determined drunkenness narrative (Measham and Brain, 2005), sensible drinkers might be seen as those who exercise self-control and do not readily abandon themselves to intoxication. Further, this notion of self-control is prominent in the traditional cogitations of masculinity meaning men should be able to 'hold' their drink by not showing the effects of heavy drinking on their bodily comportment or verbal agility (Gefou-Madianou, 2002; Hunt et al, 2005; Campbell 2000; Peralta, 2007). While there is some suggestion that many men are increasingly likely to embrace a 'messy' and 'self-destructive' drunkenness (ThurnellRead, 2011a), the continued influence of socially dominant understandings of masculinity are an important insight when considering the role of restraint and selfcontrol in relation to sensible drinking practice.

Norbert Elias's (2000) account of the 'civilizing process', whereby both individuals and societies became characterised by increased levels of self-restraint and social regulation, is a relevant yet underused conceptual tool for understanding the contested concepts of desirable and undesirable drinking and drunkenness. More specifically, Elias's work describes the civilizing process as a broad historical progression by which Western European societies developed intricate rules and prohibitions relating to personal comportment, social interaction and emotive and affective expression. As individuals in these societies became increasingly interdependent, and levels of social proximity intensified, so too did a related necessity for stricter self-regulation and control emerge. This 'civilized' conduct first emerged in the gatherings of European courts and then dispersed into wider society. In this sense, Elias's use of 'civilization' shares with the Weberian theory of rationalization and Foucauldian concepts of disciplining a desire to map the longterm changes in relationships between society and individuals where the conduct of the latter has become marked with increased control and regulation (van Krieken, 2011: 26). 
Within this, and indicative of the central influence of Freud to his work (Mannell, 1990), Elias reserves particular diligence to the ways in which bodily functions, appetites and impulses, have become more strictly controlled and regulated over time. Indeed, it is in these strictures relating to cleanliness, eating and drinking, spitting and defecation that Elias seeks to demonstrate what he terms the social constraint towards self-constraint, where society transitions from external constraints (fremdzwänge), such as the duress of physical punishment or fiscal penalties, to internalised self-restraint (selbstzwänge), the boundaries of which are marked by 'thresholds of shame and repugnance' (Elias, 2000). Social prohibitions relating to standards of conduct therefore, over time, became both institutionalised and internalised.

In a special edition of The Sociological Review exploring the influence of Elias's work, Liston (2011: 161) suggests that it is necessary to view Elias's theory not as a all encompassing grand narrative but as a 'working hypothesis' requiring 'sustained empirical investigation across a range of social contexts and time periods'. As such, this article suggests that Elias's analysis of the long-term development towards standards of conduct and internalised restraint is of significant relevance to contemporary debates relating to drinking and drunkenness. In particular, it is of use in understanding perceptions of how drinking has become less civilized in recent years as reflected in concerns, noted above, that drinkers have abandon selfrestraint in favour of self-indulgent excess. As Rohloff $(2011 ; 2013)$ has noted, such moral panics involve both perceived and actual declines in standards of conduct. Walton (2014: 211), for example, suggests that a 'de-civilising process' has taken place in the latter part of the 20th century as 'leisure activities fragmented between the generations, and the old English hedonism and lack of respect for others, and for the public realm, reasserted itself, displacing the internalised restraints and conventions which had held industrial society in check'. Indeed, Elias himself (Elias and Dunning, 1986: 90) acknowledged the allure of leisure events that generate cathartic outpourings of emotion and excitement, offering a break from the everyday routine of self-control meaning that law and order 'have again and again fought bitterly against the upsurge of excitement in people, and particularly of communal excitement, as a grave disturbance'. As such, uses of Elias's concept have necessarily acknowledged that 'there are many counter-spurts within the process, so that the main trend is visible only in the long view' (Mannell, 1990: 210) and 'these are not linear processes, but characterized by accelerations, stagnations and reversals' (van Vree, 2011: 260). However, as the article seeks to demonstrate, the Eliasian concerns with restraint and self-regulated bodily comportment find frequent and often vivid illustration as they emerge from the tensions evident within drinking discourses.

\section{Research Methods and Context}


Having established that understandings of (un)problematic drinking are contested, and having outlined Elias's concept of the 'civilizing process' as being relevant to understanding changing standards of behaviour and conduct relating to drinking and drunkenness, the article explores the accounts offered by research participants drawn predominantly from two groups: first, members of the Campaign for Real Ale (CAMRA) ${ }^{\mathrm{iii}}$, a consumer group founded in 1971 to campaign for the protection and promotion of traditional beer and pubs, and, second, members of a student ale appreciation society at an English University. Qualitative research is particularly important in revealing the complicated rituals and rites, emotions and embodiments (Jayne et al, 2010) of drinking and drunkenness. This article therefore draws on a multi-sited qualitative research project conducted between August 2012 and April 2014. A total of 53 interviews were conducted with a range of participants who were selected for their ability to offer insights into real ale appreciation and therefore represent a purposive sample. While the sample of interviewees tends towards those with a strong commitment to ale in either or both their work lives and leisure practices (issues relating to the intensity of this feeling are explored elsewhere in Thurnell-Read, 2016), throughout these periods of fieldwork informal ethnographic conversations were conducted with a variety of participants in the setting which added to the more focused insights drawn from the purposive sample of interview participants.

Reflecting the gendered nature of participation in real ale appreciation, the majority of participants were male, although two of the four female interviewees held significant positions within CAMRA with the others being a respected brewer and a beer writer. The age range of participants was broad with participants ranging from nineteen to early 70 s. Social class positions were also mixed but the majority would most accurately be described as lower middle class ${ }^{1}$. The majority of interviewees were white, although one interviewee was of mixed ethnicity.

All interviews followed a semi-structured interview schedule, were recorded and later transcribed verbatim before being coded for themes including drinking patterns, attitudes to intoxication and perceptions of own drinking practices and those of others. All research participants were aware of the purpose and aims of the research undertaking and all interviewees were provided with research briefings and signed informed consent forms. To preserve anonymity, throughout the article pseudonyms have been used for all participants and care has been taken when describing organisational roles and locations so as not to identify key participants. Beyond the interviews, participation-observation was also conducted. This involved attending local CAMRA branch meetings, a number of local and national beer festival events

\footnotetext{
${ }^{1}$ Containing as it does a number of students and retirees, the precise nature of social class positions is difficult to articulate. While measures such as occupation and education generally indicated middle class social status, some interviewees came from working class backgrounds but indicated a level of social mobility across their life course and appeared to position themselves as 'respectable' middle class but with a sense of working class identity often linked to place and community.
} 
as well as AGMs and regional Conferences. Participation in the university student ale society involved attending regular society socials taking place in towns and cities close to the university campus as well as day trips to beer festivals in Manchester and Oxford and three annual beer festivals organised and run by the society on the university campus. During field work I would drink moderately with participants. Elsewhere I have discussed the methodological implications of drinking during participant-observation research (Thurnell-Read, 2011b).

\section{'Occasionally we let our hair down, most of the time we are perfectly sensible'}

For research participants, particularly those with the closest ties to CAMRA, ale drinkers were generally portrayed as being responsible drinkers who take considerable pleasure in drinking but do so in a controlled and sensible manner. Real Ale was seen as a drink that people appreciated for its taste and quality meaning achieving drunkenness was not the primary motivation for consumption. David, a senior member of the CAMRA HQ staff, for example, reflected that:

'Real Ale is not a product that people associate with excessive drinking or crime and disorder, its seen as inherently a responsible product because people drink it for its flavour rather than to go and get off their heads and it's an important difference.'

Such sentiments were also expressed at local branch level. Martin, for example, spoke of ale being a 'quality product that you appreciate for its taste not for the fact it gets you drunk' while Roger reflected on how he 'used to be that lad drinking endless pints of cheap lager' whereas 'these days it's just a couple of ales but really good ale, I really savour them'. An important element of these accounts was the fact that ale would invariably be consumed by participants in what were seen as 'proper pubs', that is smaller local drinking venues rather than chain, corporate or branded pubs, bars and nightclubs or, indeed, within the home. Oliver, a member of the salaried HQ staff, for example, asserted that:

'Our focus has been on the benefits of moderate social consumption of alcohol, particularly in terms of the benefits of alcohol being consumed in well run public houses, you know, whether there is a degree of social management in terms of people's behaviour, how much people drink, where there's clear rules in place.'

For Oliver, it is the specifically sociable context of the pub, rather than the amount and physiological effects of alcohol consumed, that define drinking as safe and socially desirable. Martin spoke of this at length and was one of several interviewees to specifically refer to the impracticality of unit measurements: 
'Now, this 21 units a week business, where does that leave me? The way I see it is I often have a pint or two at [local pub] after work. A sociable early evening drink and a chat with a colleague or some of the regulars. On a Friday maybe a few more than that. So I drink most days but I'm never really drunk'

The discourse of sensible, social drinking is prominent and is specifically contextualised as taking place in the 'local' pub which, by implication, is respectable and embedded in the social ties of the community. Drawing on Elias (2000), we can suggest that the pub is here being depicted as a place of social proximity and interdependence where individuals manage their conduct in accordance with long standing standards of social propriety.

Further, CAMRA interviewees were quick to position ale drinkers and ale drinking in contrast to the perceived problematic drinking of high street corporate drinking venues where excess is encouraged (Chatterton and Hollands, 2003, 2010; Hadfield, 2006; Hayward and Hobbs, 2007). Thus, Martin continued his reflection on the imprecision of unit guidelines by expressing concerns about other people's drinking that, unlike his own, was not characterised by self-restraint:

'Some of these who do all their drinking on a Friday or Saturday night get all their units at once and they're the ones falling over or causing trouble in town. And it's all vodka or cheap and nasty lager, so what's that doing to them'?!'

Tellingly, the 'uncivilized' body of the binge drinker is troublesome in being one that lacks self-control and is prone to 'trouble'; the 'civilized' drinking body one that, in clear contrast, is 'never really drunk'. Local branch member Bill, for example, expressed concern about the targeting of young drinkers with heavily discounted drinks promotions:

'You see the flyers on the floor all over town up near the Uni. 50p for this shot of spirits, lager for a quid all night. That message, drink drink drink, is very strong and my worry is that there is nobody there to say hold on you've had enough, you're acting a tit now.'

One of the brewers interviewed (who are analysed specifically elsewhere in ThurnellRead, 2014), Richard, raised similar concerns of 'absolutely horrible' city high streets 'absolutely awash with drunken kids' meaning 'they are not drinking in pubs, where it should be supervised...but now the kids are drinking on the street corner or in the house and no-one is supervising them'. This expression of mixed concern and disgust for the errant ways of both young drinkers concerns the lack of supervision of young people's drinking in unregulated spaces (Townshend and Roberts, 2013) and again locates the public house as the correct and proper site for sensible social drinking to take place. Such is reminiscent of Marsh and Kibby's (1992: 118) 
reporting of the preference among police officers for youth drinking to be located in the public house, as opposed to unsupervised fields and parks, as such would allow young drinkers to be apprenticed into appropriate standards of drinking comportment.

Similar to Walton's (2014: 211) discussion of 'the absence of self-regulation' emerging from the 'de-civilising' turn from the 1980s onwards and Rohloff's (2011; 2013) reference to the importance of the perceived unrestrained behaviour of others, the contemporary space of the night-time economy are seen by Bill and others as lacking regulation and control and a place where unrestrained drinkers bring shame and embarrassment on themselves by 'acting a tit'. Further still, one participant highlighted the presence of bar and nightclub security staff or 'bouncers', who impose control on customers through physical presence and the potential for violence (See Monaghan, 2002; Hobbs, 2003), as indicative of his distaste for such drinking venues. Michael, reflected that:

'I am always amazed at these places that need half a dozen burly blokes on the door just to let people into the place [laughs] I mean, what is that telling you if you need a private army just to keep the peace?!'

Such sentiments draw a clear distinction between the perceived sociability and selfrestraint of traditional pubs in contrast with the hedonistic disorder of the night-time economy where only the external constraint of the threat of violence, Elias's fremdzwänge, can impose social order.

In contrast to this was the often stated observation that beer festivals rarely if ever saw any antisocial behaviour in spite of the notable numbers of drinkers present and quantities of beer consumed, and a lack of professional staffing or security personnel. Interviewees at both national and local level supported this assertion. Bridget, a National Director with decades of CAMRA experience including organising national and local beer festivals and lan, a local branch member with considerable experience of involvement in organising local events, commented respectively:

'If you think about the thousands and thousands of people who come to our beer festivals, and the number of incidents we have of drunkenness is tiny...we always end up with people saying it's clear the audiences that come along and drink are not the ones who are just drinking to get as much alcohol down their throats as possible.'

'Most of us are fairly responsible drinkers, occasionally we let our hair down, most of the time we are perfectly sensible, and even when we have a beer festival, if you take [the branch's local] beer festival where the vast majority of people there are not CAMRA members, you were there, how many do you think were legless?' 
For CAMRA interviewees, we see that 'sensible drinking' is about social controls of the pub, or the beer festival, and of convivial drinking with a wider range of motivations then simply to achieve intoxication.

\section{'If you are sitting drinking beer you get more merry, more happy, but not wasted'}

The accounts of drinking offered by members of the student ale society draw on similar themes to those of CAMRA members and in a similar manner frequent allusions were made to social conduct and self-restraint being important facets of sensible drinking. Much of this was strikingly at odds with typical perceptions of student drinking cultures (Dempster,2011; Hubbard, 2013). Eliot, a 2nd year student, reflected that whereas 'a lot of people associate students with drinking cheap and nasty vodka, alcopops and stuff like that, cheap and in vast quantities' he was 'happy to pay for good ale in good pubs, it just tastes better. It's much more enjoyable as far as I'm concerned.' Similarly, Justin observed that:

'I've been learning more and more about different styles of beers available and you almost want to take your time with it. I enjoy the taste and I want to see what new breweries are doing, interesting things with hops, you know, you don't just knock it back like you might with other drinks.'

As with CAMRA members, the traditional pub setting featured heavily in the explanations offered by many of the student ale society members. Luke, a postgraduate research student and one of the older and longest serving members of the society, said:

'Personally what I get out of the socials is the opportunity to go to some very nice pubs, with people who are mostly there because they like the ales, they're not there to get pissed, people do invariably get pissed but that's not the primary aim of the evening...there are also a few socials when me and a few of us have just started talking to random other people in the pubs, about the ale.'

Noticeably, the pubs visited were selected for their 'traditional' sociable atmosphere and, importantly, for their range and quality of ale and were therefore understood by members as necessarily different from 'student venues' such as the bars on campus. Similarly, Charley said:

'We] build strong connections with local pubs. You find that with members, because we've been brought out into the locality... one of the reasons when we do go to say [nearby town] or [nearby city] we like to go to 'our' pubs first so nobody is throwing up in the toilets, that sort of thing. We do like to have a good rapport with landlords. When I first joined up, my first social, we went to 
[a local pub known for its range of ale] which was brilliant, your first Real Ale social and you're in a $14^{\text {th }}$ century pub, that was what it was about for me.'

The society therefore offered members a chance to escape from what they saw as a predictable, and unappealing, circuit of student orientated drinking venues. Similarly, Eden, a former Society President, suggested that a great benefit of the society was found in:

'Offering people who are stuck in that bubble a way out, saying, you know, come with us we'll show you the best pubs in [local city] and [local town]...we like that, we like the fact we have good relationships with landlords and local CAMRA groups.'

That the ale society is presented as something productive in allowing new students to escape the confines of the campus and to venture into 'real' pubs frequented by non-students and adult 'regulars' stands in contrast to the retreat from other age groups desired by other young drinkers (Townshend and Roberts, 2013).

As with the CAMRA interviewees, members of the ale society appeared to associate the more sociable atmosphere of traditional pubs with a form of drinking and drunkenness at odds with that of high street drinking venues. For Peter, who held several key society positions during the research period, the appeal of the society and its approach to alcohol consumption related to:

'The experience of sitting in a pub, drinking and talking, you know, rather than just going along straight to [local club night] or whatever every time you go out [...] If you are sitting drinking beer you get more merry, more happy, but not wasted. And you're sitting chatting with people and it's not too much noise in the background so it doesn't get too annoying...And just sitting in a pub and talk to people, you know, you don't tend to get much of that with other social groups at university.'

This description of drinking in the sociable but 'relaxed' atmosphere of the pub was also suggested by Gale who draw a similar contrast by saying 'in a Real Ale pub its very different, in general, its more relaxed I suppose than in a club and obviously my personal preference is for drinking like that rather than in clubs'.

Brenden, an American student for whom the society was a way to 'see some English culture', felt he was free to choose not to drink heavily without worrying about censure from his peers and spoke of refusing to play a drinking game: 'I did it once and just stepped out but that was fine, there was no pressure, nobody drinks to get drunk, they're there because they like ale'. The observation made by Brenden, mirrored by others, concerning the lack of pressure to drink heavily is an important one. Indeed, both Dempster (2011) and Romo (2012) have noted that in the context 
of university campuses, where heavy drinking is the norm, abstinence or moderation can become stigmatised. Yet for Brenden and others the lack of social pressure to drink to excess was a stated appeal of the ale society. During field work, for example, it was common for some members to join the group in the pub for a 'swift pint' before returning to studies or commitments with other societies.

Both during participant-observation and interviews, it became clear that many in the society actively rejected what they saw as the unappealing nature of the 'big night out' which Roberts (2013: 6) has suggested has become the 'defining 'ritual' of drinking behaviours' amongst young people in Britain. Such was vividly depicted by Justin in his assertion that he is 'not the type to down ten Jägerbombs ${ }^{i v}$ and run around campus with my arse out' nor to go to a bar for a drink and 'leave the place reeking of sick'. Likewise, Connor explained his involvement in the society in light of his aversion to the 'ritual' of the big night out:

'I dislike club music, club drinks and mostly club people [laughs] it doesn't actually end up that much cheaper after a club night because you've got to pay to get in then drinks are only one pound but you have to get 15 and then things seems like a great idea like going on somewhere else after or going and getting a kebab, which is always a mistake.'

Interestingly, Connor's opinion on clubs was twofold in that he went on to qualify his own aversion and revulsion in relation to club atmospheres with his own sense of feeling 'out of place' in such spaces. As with Michael, discussed above, several society members also referred to the presence of 'bouncers' as a reason for disliking nightclubs and certain bars. Eliot, for example, spoke of being 'pushed about the place' by a bouncer 'on a power trip' at a local nightclub while others made references to 'fights' and aggressive behaviour, or 'aggro', in accounting for their preferences for more relaxed drinking venues.

Participants reporting self-restraint and control as desired characteristics of their drinking stands in contrast to observation of the decline of personal and social constraints to public displays of drunkenness observed in other studies (Measham and Brain, 2005; Griffin et al, 2009). Strikingly, Peter's use of 'merry' and Gale's use of 'relaxed' are telling in how they contrast with recent research into young people's drinking where the language and imagery of intoxication includes references to selfdestruction and 'letting go' (Griffin et al, 2009; Hubbard, 2013). In spite of emerging evidence that moderation, or indeed abstinence, is increasingly common (McVeigh and O'Neill, 2012), interviewees appeared to associate their drinking with a more traditional style of drinking where, as Eden suggests, you 'learn to hold your drink' and not to lose control. For some participants, this was a matter of regional identity with individuals referring to their home towns in the Northwest of England or the county of Yorkshire as maintaining a particular drinking culture based around community pubs and intergenerational drinking, and a relative early age of initiation 
to drinking. Such perhaps reveals a nostalgia for the traditional associations between the public house and rites of passage into male adulthood (Hollands and Chatterton, 2010; Campbell, 2000) and for the lasting associations between alcohol and the social performance of masculinity (Hunt et al, 2005).

\section{Discussion}

So far, the article has explored the accounts given by interviewees in positioning themselves as sensible and sociable drinkers. In reflecting on these findings, this discussion section will draw on Elias to demonstrate how 'the civilizing process' can inform debates about drinking and drunkenness. The narratives offered by participants resonate with an Eliasian understanding of the civilizing process because they envisage sensible drinking as civilized behaviour which is both intrapersonal and interpersonal in that in manifests both within individuals as selfrestraint and between individuals as conformity to expected social propriety. In these accounts, sensible drinking is understood as drinking with interdependence; the hypothetical friend telling you you've 'had too much and are acting a tit', the landlord you have 'rapport' with and do not wish to offend. Further, the self-identification of research participants as sensible drinkers relies on a twofold process of reflection on their own behaviour and relational distancing from that of others.

In further developing this analysis, it is worth again reflecting on the importance of the body to Elias's concept. Thus, the civilizing process is a long term pattern whereby bodily functions become controlled or hidden as illustrated in the growth over time of taboos relating to eating, spitting, blowing one's nose and bodily functions such as defecation (Elias, 2000). Unrestrained conduct in others is greeted with repugnance and distaste and the use of terms such as 'horrible', 'cheap' and 'nasty'. In this, then, it is perhaps unsurprising that the unbounded and messy bodies of some drinkers have been a focal point in media debates about drinking and drunkenness in Britain (Thurnell-Read, 2011a, 2013). In particular, bodies are central to classed discourses of disgust and distaste where the unruly classed body equates to moral or psychological failings of the individual (Lawler, 2005: Skeggs, 2009). Paralleling Monaghan's (2014: 698) use of Elias to analyse anti-obesity health intervention policy, the drunken or obese body is posited as 'the antithesis of the self-restrained, tightly regulated and disciplined body' of the self-regulating civilized subject. Such discourses are evidently informed in numerous ways by ideas of gender, age and maturity, and social class (Haydock, 2014a, 2014b) and, as such, mean that much alcohol and public order related policy might be understood as a 'civilizing offensive' which targets particular drinkers who are constructed as problematic while neglecting others (Mitzman, 1987; Rohloff, 2013).

The salience of this becomes more apparent when returning to the observations made at the outset concerning the use of 'spatial metaphors' to rhetorically contrast British antisocial drinking with the 'civilized' social drinking of 'continental' Europe 
(Tierney, 2006; Järvinen and Room, 2007; Jayne et al, 2008). As Pratt (2011) observes in relation to law and order framing narratives such as Tony Blaire's invocation of 'yob culture' as societal breakdown, and more specifically as Plant and Plant (2009) explore in the pitch and tone of tabloid media reporting on 'binge drinking', the act of positioning the perceived behaviour of some individuals as uncivilized and morally suspect is readily inflated to the level of societal breakdown and decline. Eilias (2000: xi) reflects that 'individuals, in their short history, pass once more through some of the processes that their society has traversed in its long history'. This observation of the similarities between civilizing processes at a societal level and an individual level has particular relevance to understanding why drinking and drunkenness are such frequent touchstones in media led debates about the supposed moral and social breakdown of British society.

The regularity with which the wayward ways of 'other' drinkers was invoked by interviewees in describing their own drinking as sociable and civilised clearly indicates how sensible drinking is referentially constituted. Throughout interviews participants used the hypothetical, and implicitly working-class, binge drinker 'to act as foil' for their own identifications with a discourse of respectable drinking (Lawler, 2005: 442). Importantly, then, the article indicates a relational constitution of understandings (un)acceptable drinking practices which is conspicuously absent from policy interventions that favour quantified unit measures. However, once we take into account that many participants also appeared to be apologetic or somewhat defensive of their rejection of determined drunkenness and the excesses of the night-time economy this picture becomes more nuanced. Thus, one CAMRA member referred to himself as 'the boring old fart in the corner of the pub', while student ale society members referred to themselves as 'geeks' who were 'socially awkward' and 'out of place' in nightclubs and 'mainstream' student drinking spaces. Of use here is Wouters' $(2007 ; 2011)$ work on informalization which suggests that recent decades have seen a loosening of the compulsion towards self-restraint identified by Elias. Following such periods of informalization, Wouters suggests that those sticking to old forms of mannered conduct might be disparaged as 'bores' who, in repressing their drives and emotions, are too 'stiff' (Wouters, 2011: 152). The apologetic tone in some interviewees descriptions of not liking nightclubs appears to stem from a concern that they will be seen as dull, boring and lacking the ability to 'let go'. Through this, an interesting and unexpected tension emerged. Participants appeared to valorise a more traditional, and often implicitly masculine, style of pub based drinking (Spracklen et al. 2013) whilst acknowledging the wider changes which made them, in Tristan's words, 'a niche interest' compared to dominant styles of drinking involving a conscious and desired letting go of inhibitions and restraint. Yet, if recent statistical evidence (ONS, 2015) is to be born out as indicative of a wider trend, many young Britons may, just like Tristan and others in the university ale society, be turning away from hedonistic excess of the night-time economy (Measham, 2008). 


\section{Conclusion}

This article has explored the drinking practices of ale drinkers and, in so doing, illustrated the complex nature of 'sensible' drinking as it is understood by individuals and performed in practice. In contrast to the emphasis on unit measurements and guidelines espoused by much alcohol policy, all participants spoke of behaviour, conduct and context, rather than quantified units of alcohol consumed, as measures of what constituted safe, sociable drinking. The discourses employed drew on notions of self-control and moderation where a sociable 'merriment' replaced more spectacular and destructive forms of intoxication. Building upon Yeoman's (2013) analysis of moderation in this journal, the present analysis has contributed to understandings of what might be seen as a middle-range of intoxication, neither abstinence nor excess, which is thus far underexplored in academic research and only poorly addressed in public talk of 'moderation' and the 'sensible drinking message' of public health policy. Further, there are indications of the difficulty with which such a balance is found and maintained meaning many of the younger interviewees spoke of their moderation in apologetic tones. Thus, against a backdrop of normative excess, itself possibly related to a recent 'process of informalization and the emancipation of emotions' identified by Wouters (2011: 141), restrained and controlled drinking, while encouraged in official policy discourse, might in fact be marginalised in specific settings such as university social spaces. A further contribution of the article is therefore to warn against sweeping generalisations based on age that tend to treat 'youth drinking' as a unitary entity, and a problematic one at that.

While Elias and his work have fallen in and out of fashion, the study of the contested debates around sensible and problem drinking attest that 'civilization continues to be an important conceptual and rhetorical reference point' (van Krieken, 2011: 25). As Liston (2011: 174) observes, Elias intended his work to foster an understanding of human beings 'in the round', meaning that movements, emotions and bodies are considered alongside rationalities and judgements. The narratives offered by research participants suggest a need for further empirical research into moderation and its relationship to both actual drinking practise and subjective understandings of those practices, loaded as they are with class-based distinctions. While the study was limited to what might be seen as a particular ale appreciation 'scene' which is almost 'subcultural' (Spracklen et al, 2013), findings indicate how discourses of sensible drinking might be better understood with greater reference to the peculiarities of drinking practice and conduct might be better understood when framed by the Eliasian conception of the civilizing process. Further, the article goes some way to redress the tendency for media, policy and academic attention to be drawn to the spectacularity of the night-time economy and in so doing to overlook a variety of drinking spaces, contexts and practices.

\section{References}


Andrews, H., (2011), The British on holiday: charter tourism, identity and consumption, Bristol: Channel View.

Ball, D., Williamson, R. and Witton, J. (2007), 'In celebration of sensible drinking', Drugs: education, prevention and policy, 14(2): 97-102.

Bourdieu, P. (1984), Distinction: A social critique of the judgement of taste, London: Routledge \& Kegan Paul.

Brown, R. and Gregg, M. (2012), 'The Pedagogy of Regret: Facebook, binge drinking and young women', Continuum: Journal of Media and Cultural Studies, 26(3): 357-369.

Cabinet Office, (2004), Alcohol Harm Reduction Strategy for England, London: The Prime Ministers Strategy Unit.

Campbell, H. (2000), 'The glass phallus: Pub(lic) masculinity and drinking in rural New Zealand', Rural Sociology, 65(4): 562-581.

Chatterton, P. and Hollands, R. (2003), Urban nightscapes: Youth cultures, pleasure spaces and corporate power, London: Routledge.

Coleman, L. and Cater, S. (2003), 'What do we know about young people's use of alcohol', Education and Health, 21(3): 50-5.

Dempster, S. (2011), 'I Drink, Therefore I'm Man: Gender discourses, alcohol and the construction of British Undergraduate Masculinity', Gender and Education, 23(5): 635-653.

Douglas, M. (1987), Constructive drinking: Perspectives on drinking from anthropology. Cambridge: Cambridge University Press.

Eldridge, A. and Roberts, M. (2008), 'A Comfortable Night Out? Alcohol, drunkenness and inclusive town centres', Area, 40(3): 365-374.

Elias, N. (1969), The Civilizing Process [Vol 1]: The history of manners, Oxford: Blackwell.

Elias, N. (1982), The Civilizing Process [Vol 2]: State formation and civilization, Oxford: Blackwell.

Elias, N. (2000), The Civilizing Process, Oxford: Blackwell. 
Elias, N. and Dunnin, E. (1986), Quest for Excitement: Sport and leisure in the civilizing process, Oxford: Blackwell.

Engineer, R., Phillips, A., Thompson, J. and Nicholls, J. (2003), 'Drunk and disorderly: a qualitative study of binge drinking among 18- to 24-year-olds', Home Office Research Study 262, London: Home Office Research, Development and Statistics Directorate.

Fox, K. (2005), Watching the English: The hidden rules of English behaviour, London: Hodder.

Gefou-Madianou, D. (2002), Alcohol, Gender and Culture, London: Routledge.

Hadfield, P. (2006), Bar Wars: Contesting the night in contemporary British cities, Oxford University Press: Oxford University Press.

Haydock, W. (2014), "20 tins of Stella for a fiver': The making of class through Labour and Coalition government alcohol policy', Capital \& Class, 38(3): 583-600.

Haydock, W. (2014), 'The 'civilising' effect of a 'balanced' night-time economy for 'better people': class and the cosmopolitan limit in the consumption and regulation of alcohol in Bournemouth', Journal of Policy Research in Tourism, Leisure and Events, 6(2): 172-185.

Hayward, K. and Hobbs, D. (2007), 'Beyond the binge in 'booze Britain': market-led liminalization and the spectacle of binge drinking', The British Journal of Sociology, 58(3): 437-456.

HM Government, (2007), Safe. Sensible. Social. The Next Steps in the National Alcohol Strategy, HM Government.

HM Government, (2012), The Government's Alcohol Strategy, HM Government.

Hobbs, D. (2003), Bouncers: violence and governance in the night-time economy, Oxford University Press.

Hollands, R. and Chatterton, P. (2010), 'Changing Times for an Old Industrial City: Hard times, hedonism and corporate power in Newcastle's nightlife', City, 6(3): 291315.

Hubbard, P. (2013), 'Carnage! Coming to a town near you? Nightlife, uncivilised behaviour and the carnivalesque body', Leisure Studies, 32(3): 265-282. 
Hunt, G., MacKenzie, K. and Laidler, K.J. (2005), 'Alcohol and Masculinity: The case of ethnic youth gangs', in Wilson, T.W. (ed.) Drinking Cultures: Alcohol and identity, Oxford: Berg. 225-254.

Interdepartmental Working Group, (1995). Sensible Drinking, London: Department of Health.

Järvinen, M. and Room, R. (2007), Youth Drinking Cultures: European experiences, London: Ashgate.

Jayne, M., Valentine, G. and Holloway, S. (2008), 'Fluid Boundaries - British Binge Drinking and European Civility: Alcohol and the production and consumption of public space', Space and Polity, 12(1): 81-100.

Jayne, M., Valentine, G. and Holloway, S. (2010), 'Emotional, embodied and affective geographies of alcohol, drinking and drunkenness', Transactions of the Institute of British Geographers, 35(4): 540-554.

Latham, A. (2003), 'Urbanity, Lifestyle and Making Sense of the New Urban Cultural Economy: Notes from New Zealand', Urban Studies, 40(9): 1699-1724.

Lawler, S. (2005), 'Disgusted subjects: The making of middle-class identities', The Sociological Review, 53(3): 429-446.

Marsh, P., and Kibby, K. F. (1992), Drinking and Public Disorder, London: Portman Group.

Mass Observation, (1943), The Pub and the People: A Worktown Study, London: Gollancz.

McVeigh, T. and O'Neill, G. (2012). 'Meet the New Puritans: young Britons cut back on drink and drugs', The Guardian, 8 December 2012.

Measham, F. (2008), 'The turning tides of intoxication: young people's drinking in Britain in the 2000s', Health Education, 108(3): 207-222.

Measham, F. and Brain, K. (2005), 'Binge Drinking, British Alcohol Policy and the New Culture of Intoxication', Crime, Media and Culture, 1(3): 262-283.

Mitzman, A. (1987), 'The civilizing offensive: mentalities, high culture and individual psyches', Journal of Social History, 20(4): 663-687.

Monaghan, L. F. (2002), 'Hard men, shop boys and others: embodying competence in a masculinist occupation', The Sociological Review, 50(3); 334-355. 
Monaghan, L.F. (2014), 'Civilising Recalcitrant Boys' Bodies: Pursuing social fitness through the anti-obesity offensive', Sport, Education and Society, 19(6): 691-711.

Nicholls, J. (2009), The Politics of Alcohol: A history of the drink question in England, Manchester: Manchester University Press.

ONS (2015), 'Statistical bulletin: Adult Drinking Habits in Great Britain, 2013'. London: Office of National Statistics.

Peralta. R. (2007), 'College Alcohol Use and the Embodiment of Hegemonic Masculinity Among European American Men', Sex Roles, 56(11-12): 741-756.

Plant, M. and Plant, M. (2006), Binge Britain: Alcohol and the national response, Oxford: Oxford University Press.

Pratt, J. (2011), 'Norbert Elias, the civilizing process and penal development in modern society', The Sociological Review, 59(1): 220-240.

Roberts, K., Townsend, T., Pappalepare, I., Elridge, A. and Mulyawan, B. (2012), Local Variations in Youth Drinking Cultures, Joseph Rowntree Foundation.

Roberts, M. (2013), 'A Big Night Out: Young people's Drinking, Social practice and spatial experience in the 'liminoid' zones of English night-time cities', Urban Studies, Online First.

Rohloff, A. (2013), 'Moral Panics as Civilizing and De-Civilizing Processes? A Comparative Discussion', Política y Sociedad, 50(2): 483-500.

Rohloff, A. (2011), 'Shifting the focus? Moral panics as civilizing and decivilizing processes' in Hier, S.P. (ed) Moral Panic and the Politics of Anxiety, London: Routledge. 71-85.

Romo, L.K. (2012), "Above the Influence': How college students communicate about the healthy deviance of alcohol abstinence', Health Communication, 27(7): 672-681.

Skeggs, B. (2009), 'The moral economy of person production: the class relations of self-performance on 'reality' television', The Sociological Review, 57(4): 626-644.

Smith, O. (2014), Contemporary Adulthood and the Night-Time Economy, London: Palgrave Macmillan. 
Spracklen, K., Laurencic, J. and Kenyon, A. (2013), "Mine's a Pint of Bitter': Performativity, gender, class and representations of authenticity in real-ale tourism', Tourist Studies, 13(3): 304-321.

Thurnell-Read, T., (2011a), "'Off the leash and out of control": masculinities and embodiment in Eastern European stag tourism', Sociology, 45 (6): 977-991.

Thurnell-Read, T., (2011b), "Common-sense" research: senses, emotions and embodiment in researching stag tourism in Eastern Europe', Methodological Innovations Online, 6 (3): 39-49.

Thurnell-Read, T., (2013), "Yobs" and "snobs": embodying drink and the problematic male drinking body', Sociological Review Online, 18 (2): 3.

Thurnell-Read, T., (2014), 'Craft, tangibility and affect at work in the microbrewery', Emotion, Space and Society, 13: 46-54.

Thurnell-Read, T. (ed.), (2015), Drinking Dilemmas: Space, Culture and Society, Abingdon: Routledge/British Sociological Association Sociological Futures Series.

Thurnell-Read, T., (2016), "'Real ale" enthusiasts, serious leisure and the costs of getting "too serious" about beer', Leisure Sciences, 38 (1): 68-84.

Tierney, J. (2006), 'We want to be more European': the 2003 Licensing Act and Britain's night-time economy', Social Policy and Society, 5(4): 453-460.

Townshend, T. and Roberts, M. (2013), 'Affordances, Young People, Parks and Alcohol Consumption', Journal of Urban Design, 18(4): 494-516.

Valentine, G., Holloway, S.L. and Jayne, M. (2010), 'Contemporary Cultures of Abstinence and the Nighttime Economy: Muslim Attitudes towards alcohol and the implications for social cohesion', Environment and Planning A, 42(1): 8-22.

van Krieken, R. (2011), 'Three faces of civilization: 'In the beginning all the world was Ireland", The Sociological Review, 59(1): 24-47.

Walton, J. (2014), 'From institution to fragmentation: the making and unmaking of the British weekend', Leisure Studies, 33(2): 202-214.

Wouters, C. (2007), Informalization: Manners and emotions since 1890, London: Sage.

Wouters, C. (2011). 'How civilizing processes continued: towards an informalization of manners and a third nature personality', The Sociological Review, 59(1): 140-159. 
Yeomans, H. (2011), 'What did the British temperance movement accomplish? Attitudes to alcohol, the law and moral regulation', Sociology, 45(1): 38-53.

Yeomans, H. (2013), 'Blurred visions: experts, evidence and the promotion of moderate drinking', The Sociological Review, 61(2): 58-78.

\footnotetext{
' One unit is $10 \mathrm{ml}$ of pure alcohol and is equivalent to a $25 \mathrm{ml}$ measure of average spirits such as vodka or whisky, or roughly half a pint of average strength beer.

ii The Civilizing Process was first published in English in two volumes only to be later revised as a single volume edition regarded as being both a more accurate translation of Elias's original text and a more refined exposition of the theories contained therein. On this basis, in the remainder of the article the 2000 revised edition is used as the primary source.

iii At the time of writing CAMRA has a membership approaching 170,000 and a salaried staff of over 30 based at their St Albans Headquarters. The organisation is formed by over 200 local branches with organisation strategy and development overseen by a 12-strong elected National Executive of voluntary, unpaid, National Directors. For more details see: http://www.camra.org.uk/.

${ }^{\text {iv }}$ A Jägerbomb is a drink created by dropping a shot glass of the German liquor Jägermeister into a larger glass of an energy drink such as Red Bull and typical 'downed' in one gulp with the mixing of alcohol and caffeine intended to bring on rapid intoxication. Jägerbombs have proved popular in student drinking venues and have gained considerable cultural visibility including media attention relating to health risks. See: Shammas, J. (2015) "Jagerbombs left me for dead': Teenager suffered three heart attacks before being saved by defibrillator', The Mirror, 4 March 2015: http://www.mirror.co.uk/news/real-life-stories/jagerbombs-left-dead-teenagersuffered-5269544.
} 